\title{
Automobile General Equipment Department Workshop Warehousing System Simulation Study
}

\author{
Daijun Pi, Qingsong Li \\ School of Transportation \& Automotive Engineering, Xihua University, Chengdu, 610039, China
}

\begin{abstract}
In this paper, firstly the workshop warehousing system was briefly discussed, storage model which demand is random variable was used to inventory modeling and analysis for an automobile general equipment department workshop warehousing system, algorithm had been designed to solve it, the best inventory strategies had been Looking under the condition that the demand was random variable. Then the WITNESS simulation software was adopted to research on workshop warehousing system, at the same time the demand order system of station was simulated. Under the condition that the flow path was unimpeded we studied to find the best strategies, to improve the order satisfaction rate and the system efficiency, and achieved the purpose of optimizing the whole system. Finally, through the example the feasibility of optimization design was verified.
\end{abstract}

Keywords-automobile; workshop warehousing; WITNESS; simulation; optimization.

\section{INTRODUCTION}

Automobile manufacturing industry is one of the pillar industries in China's national economy. Annual production and sales of China's auto industry in 2013 both have exceeded 20 million, and once again set a world record. China has won the first in the world for five consecutive years. No matter in sales, or in the model species, China's regarded as automotive powerhouse. However embarrassing is that China's passenger car brand market share has declined year by year. Mainly because in the production management, technology, quality, production scale, and testing, etc. compared with the automotive industry advanced level of the world's developed countries, China are far apart. In short, the Chinese automotive industry has developed rapidly, but the problem is also outstanding.

In the automotive workshop production management, workshop warehousing system has become an important means to conserve resources, reduce production costs, improve productivity, thereby improve their overall operational effectiveness. In the workshop and warehouse management aspects, Wang Fengzhen researched on inventory allocation model based on the demand correlation among cargo[2]. Chen $\mathrm{Lu}$ proposed a mixed integer programming model of optimization modeling, designed a two-stage optimization algorithm based on the directed connection graph for the initial solution, and used tabu search algorithm to improve the obtained solution[3]. Liu Sainan put forward cargo-space coupled reservoir allocation policy based on the mapping, which built on the general reservoir region allocation policy[5]. These articles are professional to research on workshop warehouse system, but they haven't validated the theories they made.

In this paper, firstly the workshop warehousing system was briefly discussed, storage model which demand was random variable was used for inventory modeling and analysis for an automobile general equipment department workshop warehousing system, algorithm had been designed to solve it, the best inventory strategies had been Looking under the condition that the demand was random variable. then the WITNESS simulation software was adopted to simulation research on workshop warehousing system, at the same time the demand order system of station was simulated. Finally, through the example the feasibility of optimization design was verified.

\section{THE DESCRIPTION OF THE PROBLEM}

The workshop warehouse operation starts from warehouse receiving material, ends the material have been sent to the required position in good condition and timely according to the needs. Workshop production warehouse layout $\mathrm{CAD}$ drawing is shown as follows:

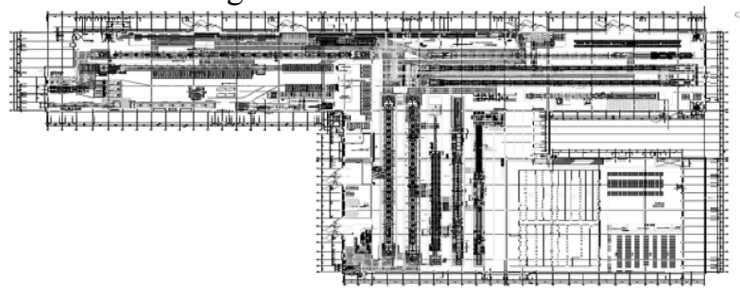

Figure 1. General equipment department workshop warehousing layout CAD

Order processing: firstly judging whether the current storage capacity is not more than $s$, if it's not more than $\mathrm{s}$, the order request should be sent to the supplier. The ordering quantity is $\mathrm{Q}=\mathrm{S}-\mathrm{s}$. On the other hand, do not order. In this paper the demand of the station is considered.

Storage processing: the general equipment department workshop cargo are many kinds, but we can assume that the cargo were divided into three categories to study. The distribution of the three types of cargo is uniform, after the cargo arriving, they need to be inspected. cargo inspected are sent to the staging area to wait for a forklift to the appropriate storage spaces.

Delivery Processing: Cargo demand in assembly 
workshop on each station is random and discrete. Assuming the selection of the three type categories is uniform. After each kind of cargo received the demand information in random, information is processed immediately. After the information is processed, the cargo are sent by truck directly to the needs of each station. After each station received the specified number of the cargo, the delivery processing is finished.

\section{MATHEMATICAL MODEL}

\section{A. Modeling and algorithm}

Analysis of stochastic inventory policy which demand is discrete usually consider the minimum total average cost, and the average total cost include storage fee $\mathrm{C}_{1}$, shortage fee $\mathrm{C}_{2}$, and ordering fee $\mathrm{C}_{3}$. Ordering fee analysis: including subscription fees and costs of cargo:

$$
C_{3}+K Q=C_{3}+K(\mathrm{~S}-\mathrm{I})
$$

Storage cost analysis: when a station needs $r<S$, parts of cargo failed distribution need to pay the storage fee. When $r \geq S$, do not need to pay storage fees (To simplify the model, this does not consider the storage fee of the cargo that have been delivered to the station), so the average value of the storage fee is:

$$
\sum_{r \leq S} C_{1}(\mathrm{~S}-\mathrm{r}) \mathrm{P}(\mathrm{r})
$$

Shortage fee analysis: when a station needs $r>S$,part of (r-S) need to pay the shortage fee. the average value of the shortage fee is:

$$
\sum_{r>S} C_{2}(\mathrm{r}-S) \mathrm{P}(\mathrm{r})
$$

Analysis of the total average cost:

$$
C(\mathrm{~S})=\mathrm{K}(\mathrm{S}-\mathrm{I})+\sum_{r \leq S} C_{1}(\mathrm{~S}-\mathrm{r}) \mathrm{P}(\mathrm{r})+\sum_{r>S} C_{2}(\mathrm{r}-S) \mathrm{P}(\mathrm{r})
$$

The random probability value of the station needs $r$ are arranged in order in size $\mathrm{ri}<\mathrm{ri}+1(\mathrm{i}=0,1, \ldots, \mathrm{m}-1)$. When the value of $\mathrm{S}$ is ri, denoted as $\mathrm{Si}$, seek the value of $\mathrm{S}$ to make $\mathrm{C}(\mathrm{S})$ minimum. In order to make the $\mathrm{C}(\mathrm{Si})$ the minimum, Si should satisfy the inequality $(2.5)$

$$
C\left(\mathrm{~S}_{i+1}\right)-\mathrm{C}\left(\mathrm{S}_{i}\right) \geq 0 ; C\left(\mathrm{~S}_{i}\right)-\mathrm{C}\left(\mathrm{S}_{i-1}\right) \geq 0
$$

Through formula (2.5) it can be deduced:

$$
\sum_{r \leq S_{i-1}} P(\mathrm{r})<N=\frac{C_{2}-K}{C_{1}+C_{2}} \leq \sum_{r \leq S_{i}} P(\mathrm{r})
$$

When satisfy the formula (2.6), $\mathrm{S}$ is the best storage.

If this stage is not to order, the total average cost is:

$$
\sum_{r \leq s} C_{1}(\mathrm{~S}-\mathrm{r}) \mathrm{P}(\mathrm{r})+\sum_{r>s} C_{2}(\mathrm{r}-\mathrm{S}) \mathrm{P}(\mathrm{r})
$$

If this stage is to order, the total average cost is:

$$
C_{3}+K(\mathrm{~S}-\mathrm{s})+\sum_{r \leq s} C_{1}(\mathrm{~S}-\mathrm{r}) \mathrm{P}(\mathrm{r})+\sum_{r>s} C_{2}(\mathrm{r}-\mathrm{S}) \mathrm{P}(\mathrm{r})
$$

If the stage is not to order, it can save a ordering fee to C3. Therefore, we assume there existence a number of S (s $=\mathrm{S})$ to make the formula (2.9) set up:

$$
\sum_{r \leq s} C_{1}(\mathrm{~S}-\mathrm{r}) \mathrm{P}(\mathrm{r})+\sum_{r>s} C_{2}(\mathrm{r}-\mathrm{S}) \mathrm{P}(\mathrm{r}) \leq C_{3}+K(\mathrm{~S}-\mathrm{s})+\sum_{r \leq s} C_{1}(\mathrm{~S}-\mathrm{r}) \mathrm{P}(\mathrm{r})+\sum_{r>s} C_{2}(\mathrm{r}-\mathrm{S}) \mathrm{P}(\mathrm{r})
$$

If the formula (2.9) holds true, no ordering is reasonable; otherwise, we should order, the order quantity is $\mathrm{Q}=\mathrm{S}-\mathrm{I}$. After finishing formula (2.9) we can obtained inequality (2.10):

$$
K s+\sum_{r \leq S} C_{(}(\mathrm{s}-\mathrm{r}) \mathrm{P}(\mathrm{r})+\sum_{r>S} C_{2}(\mathrm{r}-\mathrm{s}) \mathrm{P}(\mathrm{r}) \leq C_{3}+K \mathrm{~S}+\sum_{r s s} C_{(\mathrm{S}}(\mathrm{S}-\mathrm{r}) \mathrm{P}(\mathrm{r})+\sum_{r>s} C_{2}(\mathrm{r}-\mathrm{S}) \mathrm{P}(\mathrm{r})
$$

In the formula (2.10), when $\mathrm{s}=\mathrm{S}$, because $\mathrm{C} 3>0$, the inequality is obviously right. When $\mathrm{s}<\mathrm{S}$, in formula (2.10), the average of the shortages fee in the left is greater than the average of the shortages fee in the right, but the average of the storage fee in the left is less than the average of the storage fee in the right. Between a increase and a decreases, that inequality may still be set up. Because $\mathrm{S}$ only from $\mathrm{r} 0, \mathrm{r} 1, \ldots \mathrm{rm}$, the minimum ri that make the formula (2.10) set up must be s.

\section{B. Numerical example}

The cargo in the workshop warehouse is divided into three categories, each station demand for three categories of cargo are the same probability. Through the statistical analysis of historical data to obtain probability is: $\mathrm{P}(\mathrm{r}=70)=0.1, \mathrm{P}(\mathrm{r}=80)=0.2, \mathrm{P}(\mathrm{r}=90)=\mathrm{P}(\mathrm{r}=100)=0.3, \mathrm{P}(\mathrm{r}=110$ )$=0.1$. Ordering fee $\mathrm{C}_{3}=2812$ yuan, $\mathrm{K}=837$ yuan, storage fee $\mathrm{C}_{1}=42$ yuan(the average of the various stages), shortage fee $C_{2}=1237$ fee(the average of each stage). Using the formula 2.8 to calculate the critical value of $\mathrm{N}=0.313$. Then solving $\mathrm{S}, \mathrm{S}=90$. Using the formula 2.13 to calculate the $\mathrm{S}$. when $\mathrm{S}=90$, the right end of the formula 2.13 is $92823 ; \mathrm{s}=70$, the left end of the formula 2.13 is $84567.84567<92823$, so $s=70$. The workshop warehouse storage policy is: when $\mathrm{I} \leq 70$ add storage capacity to 90; when I>70, do not add.

\section{WITNESS MODELING AND SIMULATION}

\section{A. Simulation model}

The workshop warehouse system is the typical discrete event systems. A flow chart of relationship between the number and the logical relationship is Generally used to describe such systems model, In this paper, the logic flow chart of the simulation system is shown in Figure2.In this paper the event scheduling method is used, the occurrence of each event will cause the system state changes. The system consists of three main events, namely the order ordering events, enter warehouse event, and out of warehouse events.

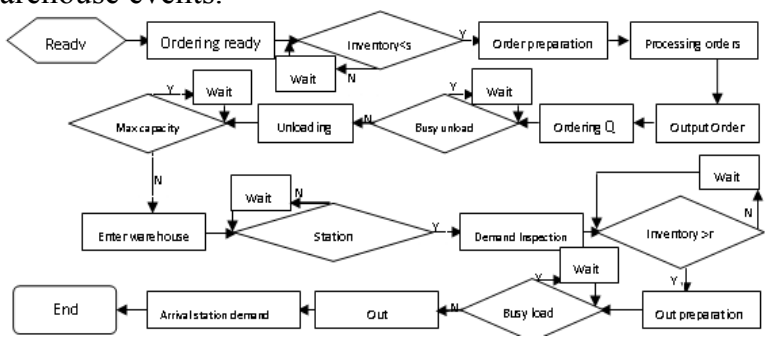

Figure 2. Simulation logic flow chart 


\section{B. Visual elements}

Visual element Description: Part elements: including three cargo (A, B, C) and three kinds of orders (Order1, Order2, Order3), In the element selection window, select the $\mathrm{P}$ element, right-click on Display, set its Text, Style; Attribute elements: Cargo attributes (Attribute Part) and order attributes (Attribute Order); Vehicle element: the element selection window, select Forklift element, right-click on Display, jump out Display dialog box, set its Style, and details of the design elements; Variable elements: storage quantity (Input Quantity), the library number (Output Quantity), order quantity (Q), reorder point (s), order number (Order Frequency) and backorders Statistics (Shortage).Workshop warehouse simulation interface is shown in Figure 3.

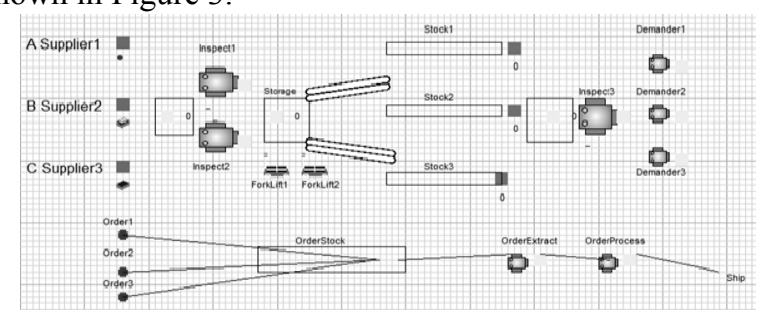

Figure 3. Workshop warehouse Simulation Operation Contact Interface

\section{Operation and data collection}

The simulation parameters are set to: Cargo: There are three different types of cargo(A, B, C), their arrival interval probability distributions are subject to UNIFORM $(1,3)$, UNIFORM $(1,4)$, UNIFORM $(2,4)$, and different types of cargo is represented by small squares of different colors. Order 1, order 2 and order3 demand probability distribution are UNIFORM $(7,14)$, UNIFORM $(8,15)$, and UNIFORM $(11,17)$. Processor: enter warehouse inspection is set two processors, out of warehouse is set up one processor, the test of time is negative exponential NEGEXP (0.5). Forklift: there are two forklift, the maximum carrying capacity is 4 , the maximum operating speed is $3 \mathrm{~m} / \mathrm{s}$. Buffer: there are two buffers, One is used for the enter warehouse, and the other is used for the out of warehouse, and its capacity is 50 units. Assuming a unit of time equivalent to the actual system simulation of 1 hour, the simulation time is set as $365 \mathrm{~d} \times 24=$ 8760 units, namely it will simulate the actual operation of the workshop warehousing one year. Repeat run the simulation model 30 times to get the average value, all the important performance indicators on the operation process of the workshop warehousing are shown in Table I \& Table III.

TABLE I. THE COST OF INVENTORY STRATEGY

\begin{tabular}{cccc}
\hline cargo & $\begin{array}{c}\text { Total } \\
\text { [yuan] }\end{array}$ & $\begin{array}{c}\mathrm{FeeC}_{1} \\
\text { [yuan] }\end{array}$ & $\begin{array}{c}\text { feeC }_{2} \\
\text { [yuan] }\end{array}$ \\
\hline $\mathrm{A}$ & 859488 & 94177 & 635136 \\
$\mathrm{~B}$ & 837896 & 89533 & 615889 \\
$\mathrm{C}$ & 874194 & 95129 & 654383 \\
Mean & 857193 & 92946 & 635136 \\
\hline
\end{tabular}

TABLE II. ORDER LEVEL

\begin{tabular}{cccc}
\hline Station demand & Max [a] & Ave [a] & Time [hour] \\
\hline Order1 & 14 & 4 & 4.2 \\
Order2 & 19 & 4 & 5.0 \\
Order3 & 15 & 7 & 4.6 \\
Mean & 16 & 5 & 4.6 \\
\hline
\end{tabular}

TABLE III. THE STAGING AREA OF THE WAREHOUSE

\begin{tabular}{cccccc}
\hline $\begin{array}{c}\text { Staging } \\
\text { Area }\end{array}$ & $\begin{array}{c}\text { Total } \\
\text { enter } \\
{[\mathrm{a}]}\end{array}$ & $\begin{array}{c}\text { Total } \\
\text { Out } \\
{[\mathrm{a}]}\end{array}$ & $\begin{array}{c}\text { Max } \\
\text { Inventory } \\
{[\mathrm{a}]}\end{array}$ & $\begin{array}{c}\text { Ave } \\
\text { Inventory } \\
{[\mathrm{a}]}\end{array}$ & $\begin{array}{c}\text { Ave } \\
\text { time } \\
{[\text { hour }]}\end{array}$ \\
\hline Enter & 85336 & 85286 & 50 & 26.24 & 4.56 \\
Out & 86149 & 85237 & 50 & 45.91 & 6.32 \\
\hline
\end{tabular}

\section{V.THE RESUlt ANALYSIS AND OPTIMIZATION}

Run the simulation model, and the simulation data were collected. The mathematical expectation of the total average cost of the three kinds of cargo in the automobile general equipment department workshop warehousing system is $857,193.00 y u a n$,among them the shortage fee is high i.e. $635,136.00 y u a n, T h i s$ shows that the inventory policies $(80,100)$ in accordance with the experience is unreasonable; The average amount of storage in the out of warehouse staging area is 45.91 (maximum storage capacity is 50), average storage time is 6.32 hours, indicates that there is a long accumulation phenomenon; Orders region's largest stocks reached 16, average inventory in the orders district is 5 , indicating that at any time there are close to five orders orders district waiting to be processed, and each order takes 4.6 days to be processed, the factors that led to this result could be that the stock in inventory area is insufficient to meet orders, there may be an inefficient storage or out operation; In order processing, only close to $87.75 \%$ of the order is satisfied, indicate the order processing the efficiency is not high.

In order to realize the smooth flow of the cargo during the warehouse operation, we can make use of the mathematical model to derive storage policy $(70,90)$, the inventory is adjusted, when the shelf stock is greater than 90 stop replenishment, when the shelf stock is less than 70 continue replenishment; at the same time adding a out warehouse processor, reduce the number of the cargo which stranded in the buffer waiting for inspection. Under the condition that the other parameters unchanged, the simulation time is also set as $365 \times 24=8760$ units, namely it will simulate the actual operation of the workshop warehousing one year. Repeat run the simulation model 30 times to get the average value.

The simulation parameters are set according to the above policy, the simulation model has been run again. The mathematical expectation of the total average cost has reduced to 400,067.00yuan; as the total shortage fee and the total storage fee in the inventory system reduced, profit has been improved. There are no longer cargo accumulation phenomenon in the three staging areas, and the number of retention is less buffer capacity. In order area, the largest inventory reduced to eight, the average stock is reduced to three, inventory time is reduced to 2.1 hours, orders 
satisfaction rate is $97 \%$, every indicators have been improved.

\section{CONCLUSIONS}

In this paper, WITNESS simulation software was used to study the workshop storage system. Under the same conditions, the initial value of the simulation model is changed to analyze and compare the indicators before and after optimization. it proved that the inventory policy optimized under certain conditions is effective to improve the efficiency of the inventory system to, and provided some technical support for the inventory system decision. Using WITNESS or other logistics simulation software to analysis of the storage system and even the workshop production system is still at the starting stage in our country, WITNESS and other logistics simulation software simulation software have large potential. If they can be fully applied to the actual, that will bring great social benefits and economic benefits.

\section{ACKNOWLEDGMENTS}

Fund Project: This paper was supported by the Innovation Fund of Postgraduate, Xihua University.

\section{REFERENCES}

[1] Steven J. Erlebacher,Russell D.Meller., The interaction of location and inventory in designing distribution systems.IIE Transactions, Feb. 2010 .

[2] Wang Fengzhen, Wang Qingbin, Based on the demand correlation A enterprise product inventory allocation policy, Dalian: Dalian Maritime University.,April 2013.

[3] Chen $\mathrm{Lu}, \mathrm{Lu}$ Zhiqiang, The storage location assignment and access path optimization in the automated warehouse. Journal of Engineering Management,January 2012.

[4] Wang Zhaoyu, Li Quanxi, The FAW Volkswagen logistics center slotting optimization research, Jilin: Jilin University, 2013.

[5] Sainan Liu, Ke Yinglin, Li Jiangxiong, Lu Zhen, Based Scheduling automated warehouse system optimization problems, Computer Integrated Manufacturing System,September 2010.

[6] Patrick Beullens, Reverse logistics in effective recovery of products from waste materials. Reviews in Environmental Science and Bio.Technology. 